\title{
Elevated serum cholesterol values preceding myocardial infarction: The need for physician referral to lipid education
}

RONALD M. LESKO, D.O, M.P.H.

DAVID E. ABBEY, PH.D

Loma Linda, California

The records of $66 \mathrm{HMO}$

patients with a discharge diagnosis of myocardial infarction were evaluated retrospectively. Only 37 patients had serum cholesterol levels noted on their charts. Just 3 of the 27 patients with a serum cholesterol value $\geqslant 240 \mathrm{mg}$. $/ \mathrm{dl}$. were referred prior to infarction to a lipid education class, which was available within this HMO as part of its preventive patient education program. Therefore, there is a need in this HMO setting to improve physician awareness of preventive medicine, including the identification of elevated serum cholesterol through screening of lipids and the availability of lipid education. The lack of physician referral of patients for preventive education is not considered to be unique to this organization.

Diet as a major factor in the development of coronary heart disease is being more widely recognized, with most of the evidence coming from epidemiologic and intervention studies. ${ }^{1-12}$ The much publicized Lipid Research Clinics Coronary Primary Prevention Trial (LRC-CPPT) $)^{13,14}$ has shown that the lowering of serum cholesterol levels with the use of the drug cholestyramine is associated with a decrease in coronary heart disease events. The reduction of serum cholesterol values by diet alone, however, may have a similar effect. Reporting on The Ireland-Boston Heart Study, Kushi and associates ${ }^{15}$ argue that the composition of the diet independently alters the risk of deaths from coronary heart disease. Results from The Leiden Intervention Trial ${ }^{16}$ also demonstrated correlation between the progression of coronary heart disease, serum cholesterol levels, and dietary intervention. Diet, therefore, appears to affect the blood lipids and possibly the rate of progression of coronary heart disease.

In December 1984, the National Institutes of Health ${ }^{1}$ held a consensus conference on the importance of lowering serum cholesterol levels in the prevention of coronary heart disease. The basic recommendation for the general public was dietary improvement rather than drug treatment.

With this fact in mind, we evaluated the practices of attending physicians in a Southern California Health Maintenance Organization (HMO) with regard to myocardial infarction patients. The purpose of the study was twofold: (1) to determine whether the patients had had laboratory testing for serum cholesterol levels at some time before their coronary event; and (2) if the serum cholesterol values had been elevated, to determine whether preventive action had been taken by the attending physician by referral of the patient to a lipid education class within the same HMO.

\section{Methods}

We reviewed outpatient records from the first three months of 1985 in which the discharge diagnosis was myocardial infarction. The records were reviewed for age, sex, height, weight, blood pressure, and preinfarction laboratory determinations of serum cholesterol levels. Cigarette use/nonuse was not recorded frequently enough to be analyzed. If the serum cholesterol value was recorded as being elevated, we checked whether the attending physician had referred the patient to the lipid education class offered at the HMO. We also noted the department of the attending physician.

Of the 68 patient records sampled, 1 could not be obtained for review, and 1 had insufficient relevant data recorded. The remaining 66 charts were evaluated. 


\begin{tabular}{|lcc|}
\hline \multicolumn{2}{|l|}{ TABLE 1. AGE DISTRIBUTION FOR 66 PATIENTS WITH MYOCAR- } \\
DIAL INFARCTION. \\
\hline $\begin{array}{c}\text { Age } \\
\text { ranges } \\
\text { (years) }\end{array}$ & \multicolumn{2}{|c|}{ Distribution } \\
\hline $31-40$ & Number & Percent \\
$41-50$ & 3 & 4.5 \\
$51-60$ & 7 & 10.6 \\
$61-70$ & 11 & 16.7 \\
$71-80$ & 21 & 31.8 \\
$81-90$ & 18 & 27.3 \\
$91-100$ & 5 & 7.6 \\
\hline
\end{tabular}

TABLE 2. CHOLESTEROL DISTRIBUTION FOR 66 PATIENTS WITH MYOCARDIAL INFARCTION.

Distribution

Cholesterol level

ranges (mg./dl.)

Not determined

160-199

200-239

$240-279$

280-319

$\geqslant 320$

\begin{tabular}{cc} 
Number & Percent \\
\hline 29 & 44.0 \\
2 & 3.0 \\
8 & 12.1 \\
19 & 28.8 \\
6 & 9.1 \\
2 & 3.0
\end{tabular}

\section{Results}

Forty-eight of the 66 outpatients were men, with an average age of 61.8 years, and 18 were women, with an average age of 71.5 years. Age range distribution is shown in Table 1.

No serum cholesterol level was ascertained before the myocardial infarction for 29 patients ( 44 percent), while testing was performed and values recorded in 37 cases (56 percent)(Table 2). Despite the fact that 27 patients had elevated serum cholesterol levels ( $\geqslant 240 \mathrm{mg}$./dl.), only 3 were referred to the lipid education class. Data regarding other serum lipid fractions (triglycerides, high-density and low-density lipoproteins) were insufficient for analysis.

To determine whether the physicians were selectively ordering serum cholesterol determinations for older patients, we compared the age distribution of the two groups. The mean age of the group tested for cholesterol levels was 65.2 years, as compared to 63.5 years for those who were not tested. A t-test indicated that these two groups did not differ significantly for age $(p=0.3)$.

The last blood pressures recorded in the patients' charts prior to myocardial infarction were examined. Nineteen were $\geqslant 140 \mathrm{~mm}$. Hg systolically, and 14 were $\geqslant 90 \mathrm{~mm}$. $\mathrm{Hg}$ diastolically. Twenty-one patients had blood pressures that were elevated either systolically, or diastolically, or both. Thirteen of the 21 patients were known hypertensives and were being treated with hypotensive agents. No blood pressure reading was recorded in 22 cases.

Quetelet's body mass index (Wt.[kg]/Ht.[m. $\left.{ }^{2}\right]$ ) was used to determine weight status. Acceptable weight has an index of 19.5 to 24.5 for men and 18.7 to 23.5 for women. Overweight classification for men has an index range of 24.6 to 27.1 and for women an index range of 23.6 to 26.8 . For men, the index for obesity is $\geqslant 27.2$, and for women $\geqslant 26.9$. Body mass index is discussed in detail by Pollock and associates. ${ }^{17}$

Twelve patients had acceptable weight status. Eight were overweight, and 20 were considered to be obese, and no weight was recorded in 26 patients; no evidence was found for referral of any of these patients to a formal weight control program.

The charts next were examined for evidence of two or three of the major risk factors for coronary heart disease-elevated serum cholesterol level, obesity, and/or uncontrolled blood pressure. (As mentioned previously, insufficient data did not allow for evaluation of smoking.) Thirteen patients ( 20 percent) had two and 5 patients ( 8 percent) had three risk factors. Only three people had no risk factors cited.

Attending physicians came from different medical departments. Thirty-nine patients had internists; 24 saw family practitioners, and 3 had physicians who were in other categories. Only 2 internists and 1 family practitioner made referrals to the lipid education class. The patients had visited physicians for a wide variety of medical problems, including cardiovascular heart disease in 23 percent of the cases.

\section{Discussion}

Only 11 percent $(3 / 27)$ of the patients with elevated serum cholesterol levels were referred to the lipid education class. These 3 cases of raised cholesterol level had been identified by a routine chemistry profile. Of the 3 patients, 1 had a history of hypertension, and another had had a recent small stroke. The third was noted only to have the high serum cholesterol value.

Other than the referral of patients to lipid education, the 3 associated physicians showed no distinct differences as compared to their peers who did not refer. However, it is realized that one referral each is not going to demonstrate any practice trends.

This low percentage of referral is surprising in view of the great attention that diet and serum cholesterol levels and their relation to coronary heart disease have been receiving. There seems to be no excuse for the lack of referral of patients with elevated lipids to the education class, particularly because the serum cholesterol values were $\geqslant 240$ $\mathrm{mg} . / \mathrm{dl}$. in 73 percent of the patients $(27 / 37)$ with known values.

Elevated serum cholesterol values and hypertension are two primary, independent risk factors for coronary heart disease. ${ }^{18}$ Data from the Framingham Heart Study ${ }^{19}$ have also shown obesity to be a possible independent risk factor. All three of these factors appear to be common to a large per- 
centage of persons who have coronary heart disease. ${ }^{18}$ It seems logical that the probability of cardiac disease becomes greater when more risk factors are present. ${ }^{20}$ Therefore, we examined elevated serum cholesterol levels along with obesity and possible uncontrolled blood pressure.

Of the 44 patients whose blood pressure reading had been recorded prior to myocardial infarction, 21 (48 percent) were elevated, according to the criteria of the Joint National Committee on Detection, Evaluation, and Treatment of High Blood Pressure. ${ }^{21}$ However, the time lapse between the last visit and the event of myocardial infarction did vary considerably (from a few weeks to a year) in all but a few cases. The elevated values for blood pressure at one reading cannot be taken to mean uncontrolled hypertension. Treated hypertensives were considered in terms of controlled blood pressure. ${ }^{21}$ Our blood pressure criterion was applied retrospectively and involved only a single reading; therefore, it should be classified as soft data.

Obesity was present in 50 percent $(20 / 40)$ of the patients. Another 8 patients were considered to be overweight according to Quetelet's index. Raised serum cholesterol added to the effect of combined risk factors in 23 percent of cases. Of the 20 obese patients, 5 (25 percent) had not had serum cholesterol testing. They accounted for 50 percent of the patients whom we could classify in a weight category.

As in any retrospective study, there is a problem with missing data. In this study, 24 percent of the 66 patients had no data recorded for one risk factor, 12 percent for two, and 23 percent for all three risk factors.

In the early era of diet therapy, the trend was to proceed on the assumption that reducing dietary cholesterol intake would lower serum cholesterol levels and perhaps the incidence of coronary heart disease as well. More recently, the beneficial effects of decreasing dietary cholesterol are becoming better documented. $1,4,6,9,10,12-16$

Previously, medical education fostered the view that the primary role of physicians was to restore health to their patients. ${ }^{22}$ Today, another approach - the prevention of disease-is playing an important role. ${ }^{23}$ This type of medicine has shown that truly "an ounce of prevention is worth a pound of cure." Such practice requires patient education, and physicians have a responsibility to direct their patients to preventive education services when indicated ${ }^{24}$ Unfortunately, physicians trained in primary care medicine find it difficult to move toward preventive services. ${ }^{25}$ They may recognize the many aspects of prevention, but they seem to be uncertain about referring patients. Perhaps they lack the time to dispense preventive information to their own patients. External factors, such as the unwillingness of insurance companies to reimburse for such services, is a present reality of the current medical system that will have to change if physicians are to be encouraged to carry out preventive education. ${ }^{26}$ Other physicians may feel that educational programs are invading their "territory." 27 Another thought is that physicians may reject preventive education because of their own need for a better lifestyle. ${ }^{28,29}$

When should patients be referred for lipid education? The National Institutes of Health consensus conference ${ }^{1}$ concluded that patients aged 40 years or older who have serum cholesterol levels $\geqslant 240$ $\mathrm{mg} . / \mathrm{dl}$. are at moderate risk for coronary heart disease. The conference encouraged a reduction of serum cholesterol levels to approximately $200 \mathrm{mg}$./ dl. for individuals 30 years of age or older. This value was chosen because it is generally agreed that serum cholesterol levels above the range of $200-230 \mathrm{mg}$./dl. significantly increases the risk of developing premature coronary heart disease. However, opinions vary. The World Health Organization $^{30}$ recommended a serum cholesterol level of $190 \mathrm{mg} . / \mathrm{dl}$. as a feasible mean for western countries. The normal range for serum cholesterol on the laboratory slip for the HMO was listed as $150-260 \mathrm{mg} . / \mathrm{dl}$.

The incidence of deaths from coronary heart disease decreases by approximately 2 percent for every 1 percent that the serum cholesterol level is lowered. ${ }^{1}$ Data obtained from the HMOs lipid education program showed a significant decrease in serum cholesterol levels (9.4 percent average reduction after 1 year) for patients who followed through with lipid education and serial serum lipid testing. Although the 3 patients who were referred to lipid education did have myocardial infarctions, it should be remembered that coronary heart disease is a multifactorial process and that elevated serum cholesterol is but one risk factor. Therefore, theoretically, at least, it is possible to decrease the incidence of coronary heart disease and its related event of myocardial infarction in the HMO. Reduction of levels of serum cholesterol is not only important in the prevention of myocardial infarction, but also in the lowering of health care costs.

Perhaps the primary care physicians in the HMO described either do not believe that referring their patients to the lipid education class will have a positive influence on the patients' future health, or they may just be ambivalent. (Should policy enforcement for patient education occur through auditing and peer review?) If the physicians are using the HMO laboratory definition of an elevated level as $>260 \mathrm{mg} . / \mathrm{dl}$., perhaps an effort should be made to lower the norm. Today, physicians must be aware of the need for reducing serum cholesterol values in patients at risk. 
In addition, because 29 patients did not have a serum cholesterol level recorded, and because some records were often more than several years old, the question of routine screening for lipids in this population arises. If at-risk patients can be identified during the time when they are subscribers to the HMO, perhaps intervention can lower the future incidence of coronary heart disease and related deaths in this prepaid care population. Ten deaths in this study were related to the patients' myocardial infarction. The serum cholesterol levels for all of these patients were $>240 \mathrm{mg}$./dl. It was noted, however, that 3 of the deaths occurred in patients with known coronary heart disease.

It is important for all physicians to become aware of preventive medical education, in whatever setting in which they are working. A survey of the 44 attending physicians in this evaluation could possibly educate the administration of the HMO to enforce better compliance from their physicians. We believe that the failure to refer patients to lipid education and/or other preventive education services may be common among physicians, and not unique to this organization. A similar, more extensive study ${ }^{31}$ at an academic health center supports this contention.

\section{Conclusions}

It has been established that dietary intervention to lower the risk of coronary heart disease is standard practice in modern medicine. Referral by primary care physicians of patients with elevated levels of serum cholesterol to preventive education programs needs improvement in this southern California HMO. By increasing patient referrals, the attending physician may aid in reducing the levels of serum cholesterol in patients with single- or multiple-risk factors for coronary heart disease, and, thereby, in decreasing the incidence of myocardial infarction and related deaths.

1. National Institutes of Health: Consensus conference. Lowering blood cholesterol to prevent heart disease. JAMA 253:2080-6, 12 Apr 85

2. Kato, H., et al.: Epidemiologic studies of coronary heart disease and stroke in Japanese men living in Japan, Hawaii, and California. Serum lipids and diet. Am J Epidemiol 97:372-85, Jun 73

3. Kahn, H.A., et al.: Serum cholesterol. Its distribution and association with dietary and other variables in a survey of 10,000 men. Israel J Med Sci 5:1117-27, Nov-Dec 69

4. Shekelle, R.B., et al.: Diet, serum cholesterol, and death from coronary heart disease. The Western Electric study. N Engl J Med 304:65-70, 8 Jan 81

5. West, R.O., and Hayes, O.B.: Diet and serum cholesterol levels. A comparison between vegetarians and non-vegetarians in a Seventh-day Adventist group. Am J Clin Nutr 21:853-62, Aug 68

6. Fraser, G.E., and Swannell, R.J.: Diet and serum cholesterol in Seventh-day Adventists. A cross-sectional study showing significant relationships. J Chronic Dis 34:487-501, 1981

7. Hardinge, M.G., Crooks, H., and Stare, F.J.: Nutritional studies of vegetarians. IV. Dietary fatty acids and serum cholesterol levels. Am J Clin Nutr 10:516-24, Jun 62

8. Malmros, H.: The relation of nutrition to health. Acta Med Scand 246S:137-53, 1950

9. Keys, A., et al:: The diet and all-causes death rate in the seven countries study. Lancet 2:58-61, 11 Jul 81
10. Morris, J.N., Marr, J.W., and Clayton, D.G.: Diet and heart. A postscript. Br Med J 2:1307-12, 19 Nov 77

11. Dayton, S., et al:: A controlled clinical trial of a diet high in unsaturated fat in preventing complications of atherosclerosis. Circulation 39-40(S2):1-63, Jul 69

12. Hjermann, I., et al.: Effect of diet and smoking intervention on the incidence of coronary heart disease. Report from the Oslo Study Group of a randomized trial in healthy men. Lancet $2: 1303-10,12$ Dec 81

13. Lipid Research Clinics Program: The Lipid Research Clinics Coronary Primary Prevention Trial results. I. Reduction in incidence of coronary heart disease. JAMA 251:351-64, 20 Jan 84

14. Lipid Research Clinics Program: The Lipid Research Clinics Coronary Primary Prevention Trial results. II. The relationship of reduction in incidence of coronary heart disease to cholesterol lowering. JAMA 251:365-74, 20 Jan 84

15. Kushi, L.H., et al.: Diet and 20-year mortality from coronary heart disease. The Ireland-Boston Diet-Heart Study. N Engl J Med 312:811-8, 28 Mar 85

16. Arntzenius, A.C., et al:: Diet, lipoproteins, and the progression of coronary atherosclerosis. The Leiden Intervention Trial. N Engl J Med 312:805-11, 28 Mar 85

17. Pollock, M.L., Wilmore, J.H., and Fox, S.M.: Medical screening and evaluation procedures. Body composition. In Exercise in Health and Disease: Evaluation and Rehabilitation, edited by M.L. Pollock. W.B. Saunders Co., Philadelphia, 1984, pp. 215-22

18. Pooling Project Research Group: Relationship of blood pressure, serum cholesterol, smoking habit, relative weight and ECG abnormalities to incidence of major coronary events. Final report of the Pooling Project. J Chronic Dis 31:201-306, 1978

19. Hubert, H.B., et al.: Obesity as an independent risk factor for cardiovascular disease. A 26-year follow-up of participants in the Framingham Heart Study. Circulation 67:968-77, May 83

20. Stamler, J.: Primary prevention of coronary heart disease. The last 20 years. Am J Cardiol 47:722-35, Mar 81

21. 1984 Report of the Joint National Committee on Detection, Evaluation, and Treatment of High Blood Pressure. Arch Intern Med 144:1045-57, May 84

22. Breslow, L.: Physician-patient partnerships for lifelong health monitoring. West J Med 141:777-81, Dec 84

23. Mason, J.O., and Tolsma, D.D.: Personal health promotion. West J Med 141:772-6, Dec 84

24. Schoenrich, E.H.: The potential of health education in health services delivery. Health Serv Rep 89:3-7, Jan-Feb 74

25. Wechsler, H., et al:: The physician's role in health promotion-a survey of primary care practitioners. N Engl J Med 308:97-100, 13 Jan 83 26. Rosen, M.A., Logsdon, D.N., and Demak, M.M.: Prevention and health promotion in primary care. Baseline results on physicians from the INSURE Project on Lifestyle Preventive Health Services. Prev Med 13:535-48, Sep 84

27. McCulloch, C., Boggs, B.J., and Varner, C.F.: Implementation of educational programs for patients. Nurs Admin Quart 4:61-8, Winter 80

28. Clever, L.H., and Arsham, G.M.: Physicians' own health-some advice for the advisors. West J Med 141:846-54, Dec 84

29. Berg, R.L.: Educating the consumer. Patient education and oreventive medicine. Bull NY Acad Med 57:80-6, Jan-Feb 81

30. World Health Organization: Prevention of coronary heart disease. Technical report series 678. World Health Organization, Geneva, 1982 31. Otradovec, K., Blake, R.L., Jr., and Parker, B.M.: An assessment of the practice of preventive cardiology in an academic health center. J Fam Pract 21:125-9, Aug 85

Accepted for publication in August 1986. Updating, as necessary, has been done by the authors.

Supported in part by a preventive medicine residency training grant (1 D33 PE 19003-01), Department of Health and Human Sciences, Public Health Service.

From the Department of Preventive Medicine, Loma Linda University Medical Center, Loma Linda, California, where Dr. Lesko was a resident in preventive medicine. Dr. Abbey is professor of biostatistics and research director, Loma Linda University, Center for Health Promotion. Dr. Lesko is an attending physician, Ambulatory Care Service, J.L. Pettis Memorial Veterans Hospital, Loma Linda, California.

Dr. Lesko, J.L. Pettis Memorial Veterans Hospital, 11201 Benton Street, 11-C, Loma Linda, California 92357. 